\title{
Studies on the Mode of Action of Tetrin A
}

\author{
By J. L. VAN ETTEN* AND D. GOTTLIEB \\ Department of Genetics, University of Pavia, Italy and \\ Department of Plant Pathology, University of Illinois, \\ Urbana, Illinois, U.S.A.
}

(Accepted for publication 13 October 1966)

\begin{abstract}
SUMMARY
Tetrin A, a polyene antifungal antibiotic, induced permeability changes in the cell membrane of Saccharomyces cerevisiae, resulting in the loss of cell constituents, e.g. amino acids, $260 \mathrm{~m} \mu$ absorbing material and the leakage of labelled metabolites from the organism previously grown with uniformly labelled glucose. Also, the uptake of glucose, glycine, and uracil was prevented by the antibiotic. Like other polyenes, the addition of exogenous cholesterol partially prevented the action of tetrin A, probably by the formation of a weak complex between tetrin A and cholesterol and resulting in a lower effective concentration of the antibiotic. When the non-sterol-containing fungus Pythium ultimum was grown on a medium containing cholesterol, this fungus was sensitive to filipin. However, prior growth of the fungus with cholesterol did not confer sensitivity to the polyene antibiotics tetrin A, nystatin, or pimaricin. Contrary to most polyene antibiotics which cause rapid lysis of mammalian erythrocytes even at low concentrations, tetrin A only caused partial lysis of calf red cells after long exposure to high concentrations.
\end{abstract}

\section{INTRODUCTION}

The modes of action of several polyene antibiotics, including filipin, nystatin, amphotericin B and pimaricin have been studied by many investigators (see reviews, Lampen, 1962; Kinsky, 1964). It is generally believed that polyene antibiotics induce permeability changes in the cell membrane of sensitive organisms causing loss of cell constituents which results in the death of the organism. Polyene-sensitive organisms bind these antibiotics, whereas insensitive bacteria and blue green algae do not. The ability of sensitive organisms to bind polyene antibiotics is apparently dependent on the presence of sterols in the cell membrane (Demel, Kinsky \& van Deenen, 1965). Tetrin, a polyene antifungal antibiotic, was discovered by Gottlieb \& Pote (1960). Further purification of the antibiotic showed that this tetrin contained two closely related compounds with antifungal activity, tetrin A and tetrin B (Rinehart, German, Tucker \& Gottlieb, 1963). The present report is concerned with the mode of action of tetrin A.

\section{METHODS}

Organisms. Most of the mycelial fungi used here in the sensitivity tests were obtained from the culture collection in the Department of Botany, University of Pavia, Italy.

* Present address: Department of Plant Pathology, University of Nebraska, Lincoln, Nebraska, U.S.A. 
Pythium ultimum and Aspergillus niger were obtained from the Department of Plant Pathology, University of Illinois, U.S.A., and Glomerella cingulata no. 10529 from the American Type Culture Collection (Rockville, Md., U.S.A.). Saccharomyces cerevisiae was obtained as an isolate from commercial Fleischmann's baker's yeast. All the fungi were maintained as slope cultures on a medium consisting of: glucose, 10 g.; yeast extract (Difco), 2 g.; agar, 20 g.; 1000 ml. water; pH 6.6 (glucose yeast extract medium). $S$. cerevisiae was grown on a reciprocal shaker at $28^{\circ}$ on a liquid medium consisting of: glucose, $10 \mathrm{~g}$; ; dehydrated yeast nitrogen base (Difco), $6.7 \mathrm{~g}$.; $1000 \mathrm{ml}$. distilled water (yeast nitrogen base medium). A 24-hr liquid culture of the yeast served as inoculum.

Testing for growth inhibition. The concentrations of tetrins A and B necessary for the complete inhibition of growth of mycelial fungi were determined by inoculating the fungi on the chemically defined agar medium of Davis \& Mingioli (1950) to which various concentrations of the antibiotics had been added. The effect of various concentrations of tetrins A and B on the growth of Saccharomyces cerevisiae was determined by extinction measurements at $540 \mathrm{~m} \mu$ of liquid cultures at given time intervals.

In all other studies with Saccharomyces cerevisiae, 12-hr cultures (log phase organisms) were used. The organisms were harvested by centrifugation, washed three times with equal volumes of distilled water, and resuspended in an equal volume of buffer or fresh medium to a final concentration equivalent to $1 \mathrm{mg}$. dry yeast $/ \mathrm{ml}$. suspending agent.

Measurement of leakage. The leakage of amino acids and $260 \mathrm{~m} \mu$ absorbing materials from Saccharomyces cerevisiae treated with tetrin A was determined in $0.1 \mathrm{M}$ citrate buffer ( $\mathrm{pH} 4$ or 6) or in $0 \cdot 1$ M-potassium phosphate buffer ( $\mathrm{pH} 8$ ). After the addition of the antibiotic to the suspension of yeasts, samples were taken at various times, centrifuged, and the supernatant fluid analysed for amino acids as ninhydrinpositive materials (Spies, 1957), and 260-m $\mu$ absorbing materials. The leakage of $260 \mathrm{~m} \mu$ absorbing materials was determined on a Beckman D.U. spectrophotometer and corrected for the absorbancy at $260 \mathrm{~m} \mu$ due to the antibiotic.

Radioactive labelling. Yeast cells labelled with radioactive metabolites were obtained by growing the yeasts in the normal medium plus [uniformly ${ }^{14} \mathrm{C}$ ]-labelled glucose at a concentration of $1 \mu \mathrm{C}$. $/ \mathrm{ml}$. After harvesting, the yeast was washed with distilled water and resuspended in fresh yeast nitrogen base medium containing the antibiotic. At various times thereafter samples were collected, centrifuged, and the supernatant fluids plated on to metal planchets to determine the residual radioactivities in them.

Measurement of tetrin A effect on metabolite uptake. The effect of tetrin A on the uptake of glucose, glycine, and uracil was determined by suspending yeast cells in glucose nitrogen base medium containing $1 \mu \mathrm{C}$. $/ \mathrm{ml}$. of [uniformly ${ }^{14} \mathrm{C}$ ]-labelled glucose (specific activity, $3.9 \mu \mathrm{C} . / \mu$ mole), [uniformly ${ }^{14} \mathrm{C}$ ]-labelled glycine (specific activity $67 \mu \mathrm{C} . / \mu \mathrm{mole}$ ) or $\left[2-{ }^{14} \mathrm{C}\right]$-labelled uracil (specific activity $30 \cdot 0 \mu \mathrm{C} . / \mu \mathrm{mole}$ ). At appropriate times, samples were removed, centrifuged, and the residual radioactivity in the supernatant fluids determined. Radioactivity was determined on a S.E.L.O. gas flow counter (counting efficiency $10 \cdot 2 \%$ ). Counts were made under conditions of negligible self-absorption. The radioactivity is expressed as counts $/$ minute (c.p.m.) $/ \mathrm{ml}$.

Effect of tetrin A on Pythium ultimum. Methods similar to those of Schlösser \& Gottlieb (1966) were used to determine the effect of tetrin A on Pythium ultimum after the fungus had been grown in the presence or in the absence of cholesterol. Pythium 
ultimum was grown on the chemically-defined medium (MM-40) of Magni \& Von Borstel (1962) and cholesterol (Applied Science Laboratories, Inc., State College, Pa., U.S.A.), $0.02 \%(\mathrm{w} / \mathrm{v})$, incorporated into the agar medium when appropriate. Following the growth of the fungus, discs were made from the advancing edge of the fungal colony with a cork borer. These discs were incubated on a reciprocal shaker for 4,8 and $12 \mathrm{hr}$. in $0.1 \mathrm{M}$-citrate buffer $(\mathrm{pH} 6.0)$ which contained various concentrations of the antibiotics (1 disc/ml. buffer). After incubation, the discs were washed in distilled water, placed on glucose yeast extract agar plates, and their growth observed by measuring the colony diameter at selected time intervals.

Calf red cells. Calf red cells were obtained by centrifuging fresh blood at $2000 \mathrm{~g}$ for $20 \mathrm{~min}$. The red cells were washed twice with an equal quantity of $0.9 \%$ sodium chloride. After the second washing, $2 \mathrm{ml}$. of the cells were resuspended in $1000 \mathrm{ml}$. $0.9 \%$ sodium chloride and samples incubated at $28^{\circ}$ with the antibiotics. At various times samples were collected, centrifuged and the extent of lysis determined by measuring at $550 \mathrm{~m} \mu$ the haemoglobin present in the supernatant solution. Total haemolysis, as determined with $20 \mu \mathrm{g}$. filipin/ml. (Kinsky, 1963), resulted in an extinction of about $0 \cdot 350$ units.

In all studies the antibiotics as well as cholesterol were dissolved in dimethylformamide. The final concentration of dimethylformamide in the suspending solution was always $0.5 \%(\mathrm{v} / \mathrm{v})$ or less. Though at these concentrations dimethylformamide had no effect on the organisms, control tubes or plates containing equal amounts of organic solvent were always used.

Polyene sources. Tetrins A and B were isolated and purified by K. Rinehart and his colleagues at the University of Illinois. Pimaricin was obtained from B. L. Hutchings, Lederle Laboratories, Pearl River, New York, U.S.A.; filipin from Upjohn Company, Kalamazoo, Michigan, U.S.A., nystatin from Lepetit S.p.A., Milan, Italy.

\section{RESULTS}

Activity of the tetrins. The concentrations of tetrins A and B necessary to prevent the growth of nine mycelial fungi are given in Table 1. Generally, tetrin A was 2 to 8 times more active than tetrin B. However, Pythium ultimum was insensitive to both tetrins, even at tetrin A $100 \mu \mathrm{g}$. $/ \mathrm{ml}$. and tetrin B $200 \mu \mathrm{g}$. $/ \mathrm{ml}$. Tetrin A also inhibited the growth of Saccharomyces cerevisiae at much lower concentrations that did tetrin B (Fig. 1). Because tetrin A was more active than tetrin B, further studies were made on tetrin A only. The death of a population of viable Saccharomyces cerevisiae exposed to several concentrations of tetrin A is shown in Table 2. More than $99.5 \%$ of yeasts were killed after $10 \mathrm{hr}$ exposure to tetrin A $100 \mu \mathrm{g} . / \mathrm{ml}$.

Effect of tetrin A on metabolite leakage and uptake. The ability of tetrin A to induce leakage of ninhydrin-positive material (mostly amino acids) and $260 \mathrm{~m} \mu$ absorbing material (nucleotides, nucleic acids) from yeasts was investigated. Tetrin $A$ induced the leakage of amino acids and $260 \mathrm{~m} \mu$ absorbing materials at concentrations in the same range as those lethal to the yeasts (Fig. 2). However, in general, the loss of amino acids occurred faster and at concentrations of tetrin A lower than those necessary for the loss of $260 \mathrm{~m} \mu$ absorbing materials. Concentrations of tetrin A, as low as $12.5 \mu \mathrm{g}$./ $\mathrm{ml}$., resulted in a fairly rapid loss of amino acids (Fig. 2B) while only a slight loss of $260 \mathrm{~m} \mu$ absorbing materials occurred at concentrations below $50 \mu \mathrm{g}$./ml. (Fig. 2A). 
Nystatin at $50 \mu \mathrm{g} . / \mathrm{ml}$. induced the loss of amino acids and $260 \mathrm{~m} \mu$ absorbing materials in a manner similar to that caused by tetrin A $100 \mu \mathrm{g} . / \mathrm{ml}$., while filipin $50 \mu \mathrm{g} . / \mathrm{ml}$. induced a more rapid leakage of these components. The optimum $\mathrm{pH}$ value of the leakage of $260 \mathrm{~m} \mu$ absorbing materials caused by tetrin A was pH 6 (Fig. 3). A similar optimum $\mathrm{pH}$ of 6 was obtained for the leakage of amino acids.

Table 1. Minimum inhibitory concentrations of tetrin $A$ and tetrin $B$

\begin{tabular}{|c|c|c|c|}
\hline \multirow[b]{2}{*}{ Fungus } & \multirow[b]{2}{*}{$\begin{array}{c}\text { Growth* } \\
\text { period } \\
\text { (hr) }\end{array}$} & Tetrin A & Tetrin B \\
\hline & & \multicolumn{2}{|c|}{$\begin{array}{l}\begin{array}{c}\text { Minimal inhibitory } \\
\text { concentration }(\mu \mathrm{g} . / \mathrm{ml} .)\end{array}\end{array}$} \\
\hline Alternaria solani & 84 & 50 & 200 \\
\hline Aspergillus niger & 48 & $12 \cdot 5$ & 100 \\
\hline Cephalosporium longiesporium & 84 & 25 & 100 \\
\hline Giberella fujikuroi & 84 & 50 & 100 \\
\hline Glomerella cingulata & 84 & 25 & 100 \\
\hline Penicillium citrinum & 48 & 100 & $>200$ \\
\hline Pythium ultimumi & 48 & $>100$ & $>200$ \\
\hline Rhizoctonia solan & 84 & 25 & 100 \\
\hline Verticillium albo-atrum & 84 & 25 & 100 \\
\hline
\end{tabular}

* Results determined after 48 or $84 \mathrm{hr}$ growth of fungi.

Table 2. Effect of tetrin $A$ on the viability of Saccharomyces cerevisiae

Initially $3.7 \times 10^{6}$ viable yeasts $/ \mathrm{ml}$. $0.1 \mathrm{M}$-citrate buffer $(\mathrm{pH} \mathrm{6.0)}$; the suspensions were incubated with shaking at $28^{\circ}$. Viable counts were made on yeast nitrogen base agar medium and colonies scored after $48 \mathrm{hr}$ incubation.

\begin{tabular}{ccccc}
$\begin{array}{c}\text { Treatment } \\
\text { period } \\
\text { (hr) }\end{array}$ & \multicolumn{4}{c}{ Concentration of tetrin A $(\mu \mathrm{g} . / \mathrm{ml})}$. \\
& $\overbrace{0}$ & 25 & 50 & 100 \\
0 & & \multicolumn{2}{c}{ Yeasts } \\
10 & 0 & 0 & 0 & 0 \\
24 & 0 & 30 & 35 & $99 \cdot 57$ \\
48 & 0 & 57 & 78 & $99 \cdot 88$ \\
& 0 & 82 & 92 & 99.98
\end{tabular}

To determine whether tetrin A could cause leakage under normal growing conditions, yeasts previously grown on labelled glucose were used. The release of radioactive materials into the medium at various times in the presence of several concentrations of tetrin A and $50 \mu \mathrm{g}$. filipin is shown in Fig. 4. Tetrin A induced a loss of labelled materials from the yeasts, but not to the same extent as did filipin.

Tetrin A inhibited the uptake of labelled glucose by yeasts in a normal growth medium (Fig. 5). In addition, glycine and uracil uptake were inhibited to the same extent by the, same concentrations of tetrin A as is shown for glucose. The uptake of these three compounds were also completely prevented by nystatin or filipin $50 \mu \mathrm{g} . / \mathrm{ml}$.

Effect of cholesterol on tetrin A activity. Because many reports (Gottlieb, Carter, Sloneker \& Amman, 1958; Gottlieb, Carter, Wu \& Sloneker, 1960; Gottlieb, Carter, Sloneker, Wu \& Gaudy, 1961; Caltrider \& Gottlieb, 1961)indicated at least partial prevention of the action of polyene antibiotics by the presence of sterols, the effect of various concentrations of cholesterol on leakage in Saccharomyces cerevisiae induced by tetrin A 


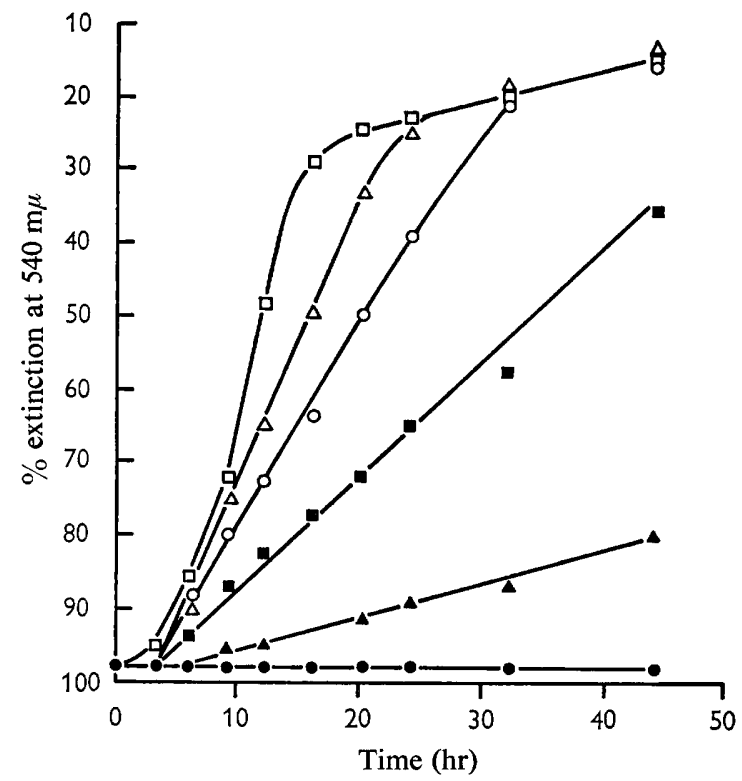

Fig. 1. The effect of various concentrations of tetrins A and B on the growth of Saccharomyces cerevisiae. $(\square)$, control or tetrin B $10 \mu \mathrm{g} . / \mathrm{ml}$.; $(\triangle)$, tetrin B $20 \mu \mathrm{g} . / \mathrm{ml}$.; $(O)$, tetrin A

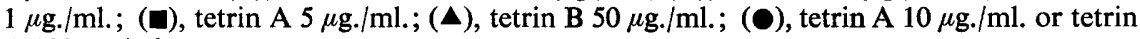
B $100 \mu \mathrm{g} . / \mathrm{ml}$.
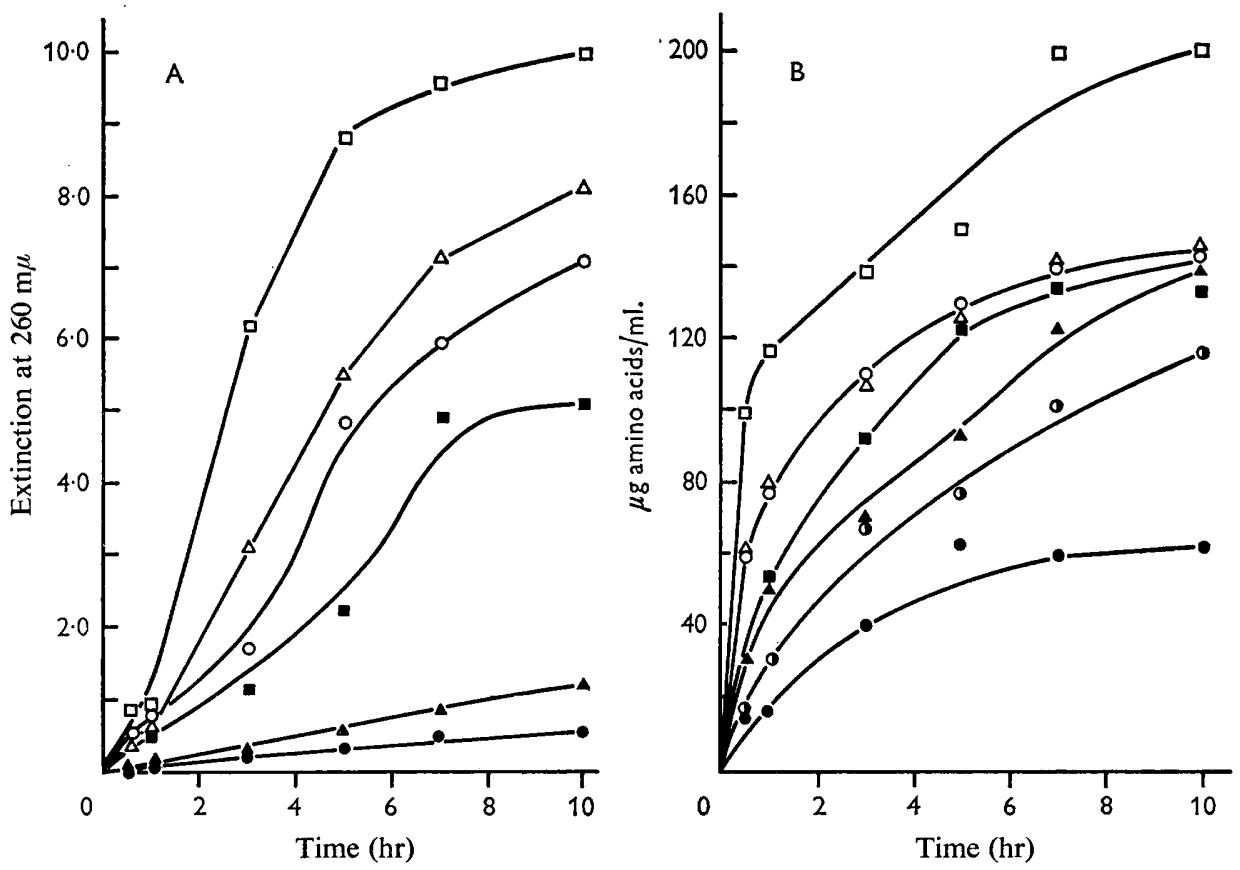

Fig. 2. Tetrin A, filipin and nystatin induced leakage of $260 \mathrm{~m} \mu$ absorbing materials (2 A) and amino acids ( $2 \mathrm{~B})$ from Saccharomyces cerevisiae suspended in $0.1 \mathrm{M}$-citrate buffer $(\mathrm{pH}$

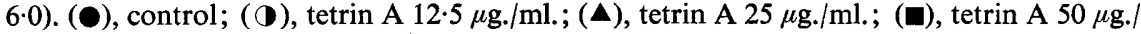
ml.; (O), tetrin A $100 \mu \mathrm{g} . / \mathrm{ml} . ;(\triangle)$, nystatin $50 \mu \mathrm{g} . / \mathrm{ml}$; ( $\square)$, filipin $50 \mu \mathrm{g} . / \mathrm{ml}$. 
was examined. Cholesterol added at the same time as tetrin $A$, at a ratio of $1: 1(w / w)$, caused a slight decrease in the loss of amino acids and $260 \mathrm{~m} \mu$ absorbing materials, while higher ratios resulted in a significant decrease (Fig. 6). Lampen, Arnow \& Safferman (1960) suggested that the inhibition of polyene action by sterols is due to the formation of a sterol-polyene complex resulting in a lower effective concentration of the antibiotic.

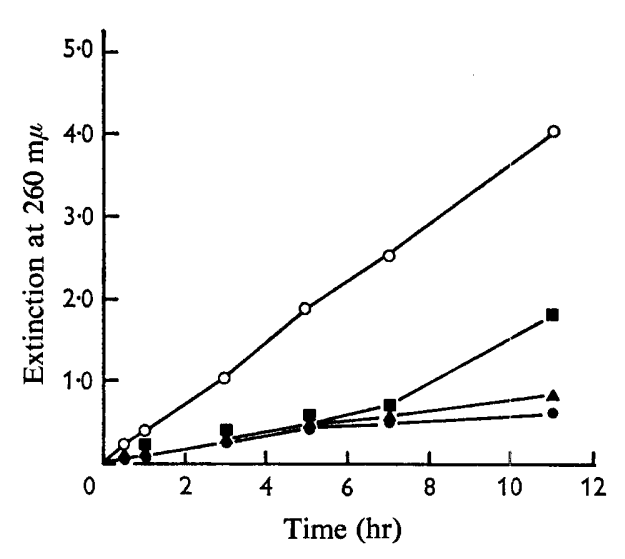

Fig. 3

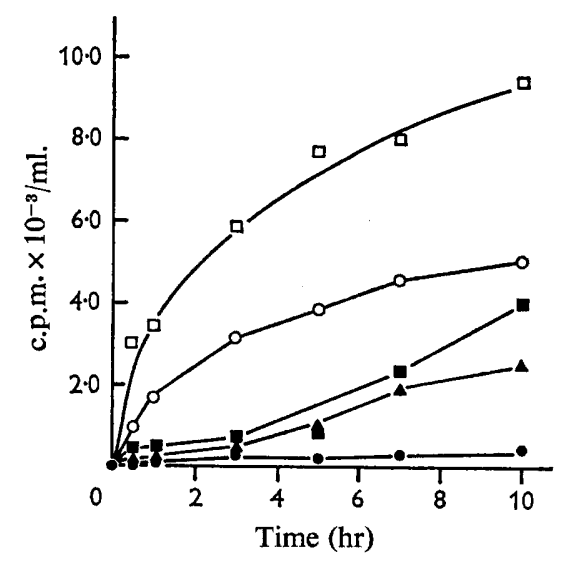

Fig. 4

Fig. 3. The effect of the $\mathrm{pH}$ value of the suspending buffer on the leakage of $260 \mathrm{~m} \mu$ absorbing materials from Saccharomyces cerevisiae exposed to tetrin A $50 \mu \mathrm{g} . / \mathrm{ml}$. (O),

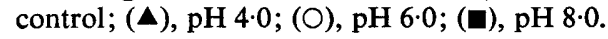

Fig. 4. Leakage of $\left[{ }^{14} \mathrm{C}\right]$-labelled materials from Saccharomyces cerevisiae in normal growth medium exposed to filipin or tetrin A. (O), control; (A), tetrin A $25 \mu \mathrm{g} . / \mathrm{ml}$.; ( $\mathbf{\square})$, tetrin A $50 \mu \mathrm{g} . / \mathrm{ml}$.; (O), tetrin A $100 \mu \mathrm{g} . / \mathrm{ml}$.; (口), filipin $50 \mu \mathrm{g} . / \mathrm{ml}$.

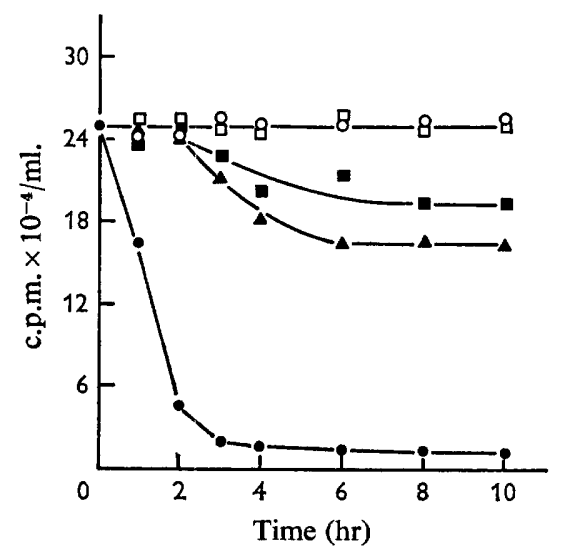

Fig. 5. Effect of tetrin A on the uptake of [uniformly ${ }^{14} \mathrm{C}$ ]-labelled glucose by Saccharomyces

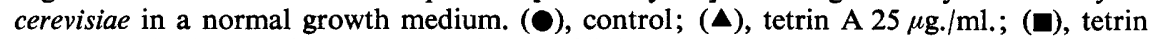
A $50 \mu \mathrm{g} . / \mathrm{ml}$; (O), tetrin A $100 \mu \mathrm{g} . / \mathrm{ml}$; ( $\square)$, filipin $50 \mu \mathrm{g} . / \mathrm{ml}$.

This might be one explanation for the observed effect of cholesterol on the leakage induced by tetrin A. For example, a ratio of cholesterol to tetrin A of $1: 1(\mathrm{w} / \mathrm{w})$ resulted in a lower extinction of tetrin A (Fig. 7). Higher ratios of cholesterol to tetrin A resulted in a further decrease in the extinction. As with other polyenes, the complex of 

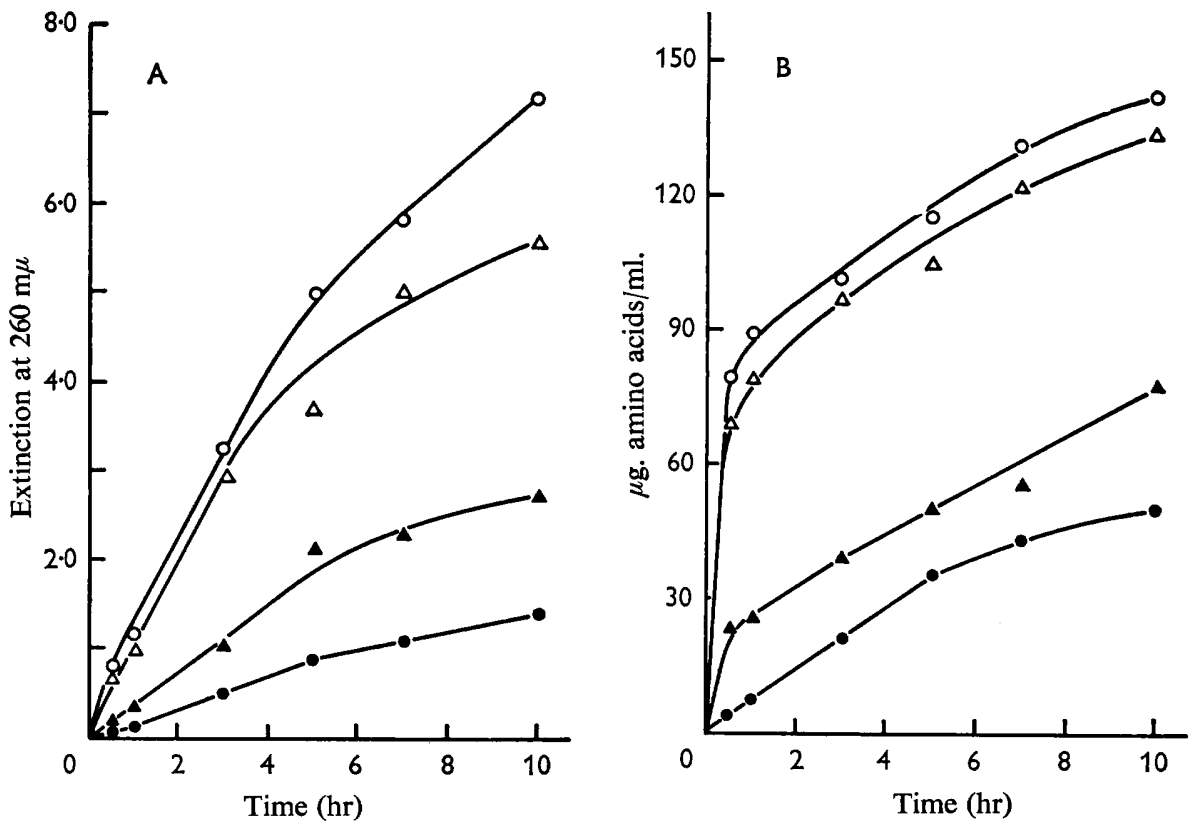

Fig. 6. The effect of exogenous cholesterol on the tetrin A $(50 \mu \mathrm{g} . / \mathrm{ml}$.)-induced leakage of $260 \mathrm{~m} \mu$ absorbing materials $(6 \mathrm{~A})$ and amino acids (6 B) from Saccharomyces cerevisiae suspended in citrate buffer (pH 6.0). (๑), cholesterol $200 \mu \mathrm{g} . / \mathrm{ml}$.; (४), tetrin A $50 \mu \mathrm{g} . / \mathrm{ml}$. + cholesterol $200 \mu \mathrm{g} . / \mathrm{ml}$.; $(\triangle)$, tetrin A $50 \mu \mathrm{g} . / \mathrm{ml}$.+ cholesterol $50 \mu \mathrm{g} . / \mathrm{ml}$; $(O)$, tetrin A $50 \mu \mathrm{g} . / \mathrm{ml}$.

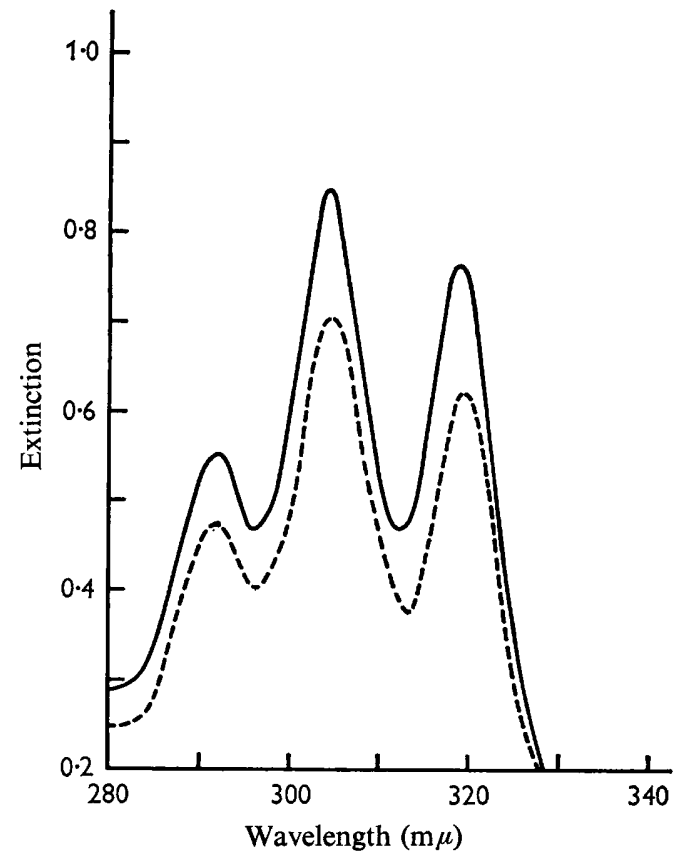

Fig. 7. Absorption spectrum of tetrin A $(10 \mu \mathrm{g} . / \mathrm{ml}$. $)$ in 0.05 M-potassium phosphate buffer (pH 6.0) in the presence (--.---) and absence (-) of cholesterol $(10 \mu \mathrm{g} . / \mathrm{ml}$. 
tetrin A with cholesterol is apparently very weak since the decrease in extinction of tetrin A caused by cholesterol was annulled by the addition of an equal volume of dimethylformamide.

Further evidence that the addition of exogenous cholesterol might be causing a lower effective concentration of tetrin A is provided in Table 3. When tetrin A $50 \mu \mathrm{g} . /$ $\mathrm{ml}$. was added to a population of viable Saccharomyces cerevisiae suspended in citrate buffer, $91 \%$ of the yeasts were killed after $48 \mathrm{hr}$. However, when cholesterol (200 $\mu \mathrm{g} . / \mathrm{ml}$.) was added at the same time as the tetrin A, only $56 \%$ of the yeasts were killed. The addition of cholesterol to the yeast suspension $24 \mathrm{hr}$ after the addition of tetrin A had no effect in restoring viability.

\section{Table 3. Effect of tetrin $A$ on the viability of Saccharomyces cerevisiae in the presence of added cholesterol}

The initial yeast suspension contained $3 \cdot 3 \times 10^{6}$ viable yeasts $/ \mathrm{ml}$. buffer. Colonies were scored after incubation for $48 \mathrm{hr}$ and rechecked after $96 \mathrm{hr}$; no differences were found. The incubation was at $28^{\circ}$ with shaking. Cholesterol was added to $200 \mu \mathrm{g} . / \mathrm{ml}$. and tetrin*A to $50 \mu \mathrm{g} . / \mathrm{ml}$.

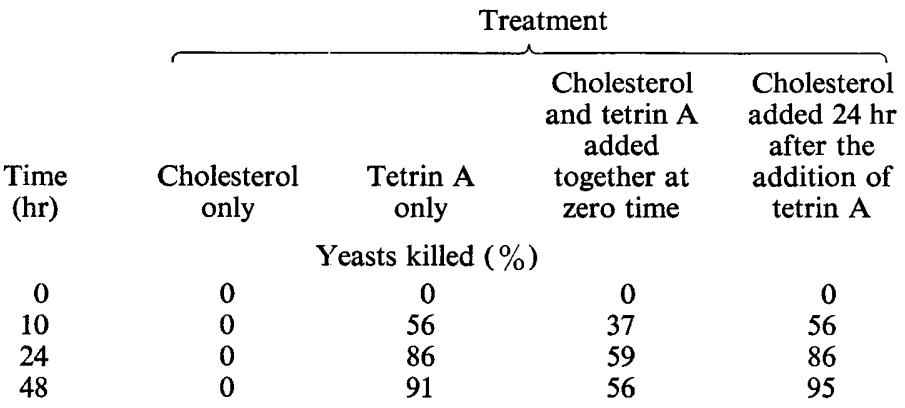

Effect of tetrin A on Pythium ultimum. Several investigators have indicated that the presence of sterols in an organism is a primary requirement for sensitivity to polyene antibiotics (see Demel, Kinsky \& van Deenen, 1965, for a summary of evidence). Therefore, the absence of sterols from fungi of the genus Pythium might explain their resistance to polyene antibiotics (Schlösser \& Gottlieb, 1966). However, Schlösser \& Gottlieb (1966) note that when these fungi were grown on a sterol (cholesterol)containing medium, they became sensitive to filipin. By using similar techniques to those of Schlösser \& Gottlieb, we found that Pythium ultimum was sensitive to filipin after prior growth on a cholesterol-containing medium. Indeed all $P$. ultimum organisms exposed to filipin $250 \mu \mathrm{g}$. $/ \mathrm{ml}$. for $4 \mathrm{hr}$ were killed, but when $P$. ultimum was grown in the absence of cholesterol it was insensitive to filipin. However, prior growth of $P$. ultimum on cholesterol-containing medium followed by exposure to tetrin A, nystatin, or pimaricin 250 or $500 \mu \mathrm{g}$. $/ \mathrm{ml}$. for periods up to $12 \mathrm{hr}$, had no effect on the resultant growth of the fungus when it was placed on fresh growth medium. Control discs of the sensitive fungus, Glomerella cingulata, were killed in less than $8 \mathrm{hr}$ in the presence of nystatin, tetrin A, or pimaricin $500 \mu \mathrm{g} . / \mathrm{ml}$.

Effect of tetrin $A$ on calf red cells. Because a previous report (Kinsky, 1963) indicated that many polyene antibiotics at low concentrations caused rapid and complete lysis of certain mammalian red cells, the effect of tetrin A on the lysis of calf red cells was examined. As shown in Table 4, tetrin A, even at $200 \mu \mathrm{g} . / \mathrm{ml}$. and after $6 \mathrm{hr}$ in- 
cubation, had little effect on the red cells, whereas, filipin at $2 \mu \mathrm{g} . / \mathrm{ml}$. caused complete lysis after a few min. Pimaricin and nystatin required higher concentrations and longer times than did filipin to cause complete lysis of the cells.

Table 4. Lysis of calf red cells by tetrin A, nystatin, pimaricin and filipin

\begin{tabular}{|c|c|c|c|c|c|c|c|c|c|c|}
\hline \multirow{3}{*}{$\begin{array}{l}\text { Time } \\
(\min .)\end{array}$} & \multicolumn{10}{|c|}{ Treatment } \\
\hline & \multicolumn{3}{|c|}{$\begin{array}{l}\text { Tetrin A } \\
(\mu \mathrm{g} . / \mathrm{ml} .)\end{array}$} & \multicolumn{3}{|c|}{$\begin{array}{l}\text { Nystatin } \\
(\mu \mathrm{g} . / \mathrm{ml} .)\end{array}$} & \multicolumn{2}{|c|}{$\begin{array}{l}\text { Pimaricin } \\
(\mu \mathrm{g} . / \mathrm{ml} .)\end{array}$} & \multirow{2}{*}{$\begin{array}{l}\text { Filipin } \\
(\mu \mathrm{g} . / \mathrm{ml} .) \\
2\end{array}$} & \multirow{2}{*}{$\begin{array}{c}\text { Control } \\
0\end{array}$} \\
\hline & 50 & 100 & 200 & 25 & 50 & 200 & 25 & 50 & & \\
\hline \multicolumn{11}{|c|}{ Lysis (\%) } \\
\hline 0 & 0 & 0 & 0 & 0 & 0 & 0 & 0 & 0 & 0 & 0 \\
\hline 15 & 0 & 0 & 11 & 6 & 6 & 28 & 8 & 100 & 100 & 0 \\
\hline 30 & 0 & 0 & - & 8 & 10 & 44 & 9 & 100 & 100 & 0 \\
\hline 60 & 0 & 4 & 18 & 14 & 20 & 69 & 10 & 100 & 100 & 0 \\
\hline 180 & 0 & 5 & 15 & 30 & 46 & 100 & 20 & 100 & 100 & 0 \\
\hline 360 & 0 & 6 & 20 & 41 & 47 & 100 & 23 & 100 & 100 & 0 \\
\hline
\end{tabular}

\section{DISCUSSION}

Tetrin A is apparently one of the least active polyene antifungal antibiotics because higher concentrations of the antibiotic are required for complete inhibition of fungal growth and for the killing of Saccharomyces cerevisiae than those reported for other polyenes (e.g. Bradley, Farber \& Jones, 1961; Gottlieb et al. 1960; Kinsky, 1961). Nevertheless, tetrin A appears to act in a manner similar to that of other polyene antibiotics, namely by disrupting the permeability properties of the cells; most likely by acting on the ergosterol in the cell membranes. The disruption of cellular permeability causes a general leakage of cellular components and prevents the uptake of essential metabolites. Various compounds have been shown to leak out of fungal cells exposed to other polyene antibiotics, including amino acids and inorganic phosphate (Caltrider \& Gottlieb, 1961), $260 \mathrm{~m} \mu$ absorbing materials (Gottlieb et al. 1961; Kinsky, 1961), carboxylic acids (Scholz et al. 1959), and potassium (Marini, Arnow \& Lampen, 1961).

Since tetrin A induced a leakage of metabolites, it is probably not surprising that the active uptake of essential compounds such as glucose, glycine and uracil was also inhibited. Stachiewicz \& Quastel (1963) reported that glycine uptake was inhibited by nystatin.

Schlösser \& Gottlieb (1966) reported that if pythium species were grown on a medium containing cholesterol the fungus became susceptible to the polyene filipin; we have confirmed such results with filipin. However, the polyenes, nystatin, pimaricin or tetrin A, even after $12 \mathrm{hr}$ incubation at higher concentrations, had no effect on the growth of Pythium ultimum when it had previously been grown on cholesterol. The inability of these three polyenes to inhibit $P$. ultimum when grown in the presence of cholesterol cannot be entirely explained on the basis of a slower rate of lysis (Kinsky, 1962; Cirillo, Harsch \& Lampen, 1964) since another fungus, Glomerella cingulata, was killed by these three antibiotics after $8 \mathrm{hr}$ incubation. Moreover, if some or most of the $P$. ultimum-cells exposed to these antibiotics had been killed, a longer time period would have been necessary for the cell colony to grow. This did not occur. 
A possible explanation for the ineffectiveness of these three polyene antibiotics may be that when the cholesterol is incorporated by the fungus, presumably into the cell membrane, it is oriented in such a manner that is accessible to the action of filipin, but not to nystatin, pimaricin, or tetrin A. Indeed, Lampen, Gill, Arnow \& Magana-Plaza, 1963 reported that a sterol requiring pleuropneumonia-like organism, Mycoplasma gallisepticum, was sensitive to low concentrations of filipin but almost insensitive to nystatin at much higher concentrations, even though both antibiotics were bound by the organism. In addition, since filipin apparently caused a more extensive reorientation of an artificial membrane than did nystatin (Demel et al. 1965), it would not be surprising if the action of filipin were slightly different. While the presence of sterol in an organism is apparently a primary requirement for sensitivity to polyene antibiotics, in itself, this is not always sufficient for sensitivity. For example, Mycoplasma laidlawii, is resistant to the polyene antibiotics filipin and amphotericin B under certain temperature conditions, even though the organism contains sterol (Weber \& Kinsky, 1965; Feingold, 1965).

Additional evidence that the alteration of the cell membrane brought about by tetrin A, nystatin and pimaricin is slightly different from that caused by filipin, and possibly other polyenes, is provided by the weaker ability of these antibiotics to induce lysis in mammalian red cells. Many polyene antibiotics, including filipin, cause rapid lysis of mammalian red cells even at low concentrations (Kinsky, 1963). Of the polyene antibiotics studied by Kinsky, nystatin and pimaricin were exceptions since higher concentrations were required for complete lysis of the red cells. Tetrin A resembled nystatin and pimaricin in this respect except that even higher concentrations of tetrin A were necessary to produce the lytic effect.

The authors acknowledge the kind assistance and helpful suggestions of Dr E. Schlösser and Dr O. Ciferri. Dr J. O. Lampen generously made the manuscript of a general review on polyenes available in advance of publication. One of the authors, J. Van Etten, was supported by a National Science Foundation Postdoctoral Fellowship, no. 45125.

\section{REFERENCES}

Bradley, S. G., Farber, P. J. \& Jones, L. A. (1961). Action of polyene antibiotics on Candida. Antimicrobial Ag. A. 1960, 558.

Caltrider, P. \& Gottlieb, D. (1961). Studies on the mode of action of filipin on Saccharomyces cerevisiae. Trans. Ill. Acad. Sci. 54, 189.

Cirillo, V. P., Harsch, M. \& Lampen, J. O. (1964). Action of the polyene antibiotics filipin, nystatin, and $N$-acetyl candidin on the yeast cell membrane. J. gen. Microbiol. 35, 249.

Davis, B. O. \& MingIoli, E. S. (1950). Mutants of Escherichia coli requiring methionine or vitamin B-12. J. Bact. 60, 17.

Demel, R. A., Kinsky, S. C. \& van Deenen, L. L. M. (1965). Penetration of lipid monolayers by polyene antibiotics. Correlation with selective toxicity and mode of action. J. biol. Chem. $240,2749$.

FEINGOLD, D. S. (1965). The action of amphotericin B on Mycoplasma laidlawil. Biochem. Biophys. Res. Comm. 19, 261.

GotTlieb, D. \& Pote, H. L. (1960). Tetrin, an antifungal antibiotic. Phytopathology 50, 817.

Gottlieb, D., Carter, H. E., Sloneker, J. H. \& Ammann, A. (1958). Protection of fungi against polyene inhibition by sterols. Science 128,361 .

GotTlueb, D., CARTer, H. E., Wu, L. \& Sloneker, J. H. (1960). Inhibition of fungi by filipin and its antagonism by sterols. Phytopathology 50, 594.

Gottlieb, D., Carter, H. E., Sloneker, J. H., Wu, L. \& Gaudy, E. (1961). Mechanism of inhibition of fungi by filipin. Phytopathology 51, 321.

KINSKY, S. C. (1961). Alterations in the permeability of Neurospora crassa due to polyene antibiotics. J. Bact. 82, 889. 
KINSKY, S. C. (1962). Effect of polyene antibiotics on protoplasts of Neurospora crassa. J. Bact. 83, 351.

KINSKY, S. C. (1963). Comparative responses of mammalian erythrocytes and microbial protoplasts to polyene antibiotics and vitamin A. Arch. Biochem. Biophys. 102, 180.

KINSKY, S. C. (1964). Membrane sterols and the selective toxicity of polyene antifungal antibiotics. Antimicrobial Agents and Chemotherapy 1963, 387.

LAMPEN, J. O. (1962). Intermediary metabolism of fungi as revealed by drug action. In Fungi and Fungus Diseases. Symp. 2 N.Y. Acad. Med., Sec. Microbiol. Springfield, Ill. U.S.A.: C. C. Thomas.

Lampen, J. O., ARnow, P. M. \& Safferman, R. S. (1960). Mechanism of protection by sterols against polyene antibiotics. J. Bact. 80, 200.

Lampen, J. O., Gill, J. W., Arnow, P. M. \& Magana-Plaza, I. (1963). Inhibition of the pleuropneumonia-like organism Mycoplasma gallisepticum by certain polyene antifungal antibiotics. J. Bact. 86, 945.

MAGNi, E. G. \& VON Borstel, R. C. (1962). Different rates of spontaneous mutation during mitosis and meiosis in yeast. Genetics 47, 1097.

MARINI, F., ARNOW, P. \& LAMPEN, J. O. (1961). The effect of monovalent cations on the inhibition of yeast metabolism by nystatin. J. gen. Microbiol. 24, 51.

Rinehart, K. L., German, V. F., Tucker, W. P. \& Gottlieb, D. (1963). Isolierung und Eigenschaften der Tetrine A und B. Justus Liebigs Annln Chem. 688, 77.

Schlösser, E. \& Gottlieb, D. (1966). Sterols and the sensitivity of Pythium species to filipin. J. Bact. 91, 1080.

Scholz, R., Schmitz, H., Bücker, T. \& LAMPEN, J. O. (1959). Über die Wirkung von Nystatin auf Bäckerhefe. Biochem. Z. 331, 71 .

SpIES, J. R. (1957). Colorimetric procedures for amino acids. In Meth. Enzym. 3, 467.

Stachiewicz, E. \& Quastel, J. H. (1963). Amino acid transport in yeast and effects of nystatin. Canad. J. Biochem. Physiol. 41, 397.

WEBER, M. M. \& KINSKY, S. C. (1965). Effect of cholesterol on the sensitivity of Mycoplasma laidlawii to the polyene antibiotic filipin. J. Bact. 89, 306. 